\section{Direct evidence for active site-dependent formic acid electro-oxidation by topmost-surface atomic redistribution in a ternary $\mathrm{PtPdCu}$ electrocatalyst $\dagger$}

\author{
Chun-Hua Cui, ${ }^{a}$ Hui-Hui Li, ${ }^{a}$ Huai-Ping Cong, ${ }^{a}$ Shu-Hong Yu*a and Franklin (Feng) Tao $* b$ \\ Received 11th August 2012, Accepted 29th October 2012 \\ DOI: $10.1039 / \mathrm{c} 2 \mathrm{cc} 35822 \mathrm{k}$
}

The active site-dependent electrochemical formic acid oxidation was evidenced by the increased coverage of $\mathrm{Pt}$ in the topmost mixed PtPd alloy layer of ternary PtPdCu upon potential cycling, which demonstrated two catalytic pathways only in one catalyst owing to surface atomic redistribution in an acidic electrolyte environment.

The design of active and robust electrocatalysts with a low $\mathrm{Pt}$ content for low temperature fuel cell processes has been one of the bottlenecks for a wide spectrum of applications of this efficient energy conversion technology. ${ }^{1}$ It has driven a significant amount of effort. One of the approaches is the synthesis of Pt-based binary and ternary electrode materials by alloying a $3 \mathrm{~d}$ and/or a less noble metal, including a $\mathrm{Pt}$ monolayer on a particle surface, ${ }^{2}$ a segregation-induced $\mathrm{Pt}$ skin, ${ }^{3}$ a Pt shell with several atomic layers by dealloying, ${ }^{4}$ a defect-free Pt surface by acid-leaching, ${ }^{5}$ and a rough Pt surface by potential-induced restructuring. ${ }^{6}$

Restructuring of bimetallic catalysts under reaction conditions has been well acknowledged. ${ }^{7}$ For example, the core-shell structured $\mathrm{Rh}_{x} \mathrm{Pd}_{1-x}$ nanoparticle catalysts can be restructured by different adsorption energy of reactant molecules on different metals and different surface energy of metals under dry conditions. $^{8}$ Under electrolytic conditions, the potential cycling-induced surface segregation in an alkaline electrolyte results in the formation of a $\mathrm{Pt}$ shell around a $\mathrm{Pt}_{x} \mathrm{Co}_{y}$ core at room temperature. ${ }^{9}$ However, until now, it has been quite difficult in a ternary alloy with a mixed noble metal alloy surface to understand the surface atomic rearrangement in an acidic electrolyte. ${ }^{10}$ Very recently, we reported the controlled synthesis of PtPdCu electrocatalysts with a mixed PtPd alloy surface, which showed enhanced catalytic activity and stability. ${ }^{11}$ We found the increase of the $\mathrm{Pt} / \mathrm{Pd}$ atomic ratio in the surface

${ }^{a}$ Division of Nanomaterials \& Chemistry, Hefei National Laboratory for Physical Sciences at Microscale, Department of Chemistry, CAS Key Laboratory of Mechanical Behavior and Design of Materials, National Synchrotron Radiation Laboratory, University of Science and Technology of China (USTC), Hefei 230026, P. R. China. E-mail:shyu@ustc.edu.cn

${ }^{b}$ Department of Chemistry and Biochemistry, University of Notre Dame, Notre Dame, Indiana 46556,USA.E-mail: ftao@nd.edu $\dagger$ Electronic supplementary information (ESI) available: TEM, cyclic voltammetry, XRD, EDX and XPS data. See DOI: 10.1039/ c2 $2 \mathrm{cc} 35822 \mathrm{k}$ region ( $\sim 3 \mathrm{~nm}$ sampling depth) measured by X-ray photoelectron spectroscopy (XPS) under potential cycling and, thus, the increased coverage of $\mathrm{Pt}$ in the topmost layer. ${ }^{12}$ This unique characteristic allows us to study the site-dependent electrocatalytic reaction in situ, such as formic acid oxidation, and understand the fundamental mechanism in electrocatalysis.

Herein, we report a site-dependent electrochemical formic acid oxidation reaction on a mixed $\mathrm{Pt} / \mathrm{Pd}$ alloy surface of ternary $\mathrm{PtPdCu}$ in an acidic electrolyte. The increased $\mathrm{Pt} / \mathrm{Pd}$ atomic ratio in the topmost surface layer changes the formic acid oxidation mechanism owing to the adsorption differences for formic acid molecules. Vice versa, this site-dependent formic acid oxidation mechanism may be developed as a probe technique to in situ tail the $\mathrm{Pt} / \mathrm{Pd}$ composition ratio change in the topmost layer.

The synthesis method of $\mathrm{PtPdCu}$ was modified using a previously reported method ${ }^{12}$ including electrochemical deposition and thermal treatment (ESI, $\dagger$ Fig. S1). Compared with the previous synthesis, in this case, to avoid the size effect and to obtain a near-extended flat metal surface (Fig. S2a, ESI $\dagger$ ), the thermal treatment was performed at a higher temperature of $500{ }^{\circ} \mathrm{C}$ for 8 hours in $5 \% \mathrm{H}_{2}$ balanced with Ar. The bulk composition of the as-synthesized material with lower Pt content is $4 \% \mathrm{Pt}, 36 \% \mathrm{Pd}$, and $60 \% \mathrm{Cu}$ (Fig. 1a).

After thermal annealing, high resolution transmission electron microscopy (HRTEM) images showed the formation of large-size plate-like particles, like an extended metal surface (ESI, $\dagger$ Fig. S2 and S3). As the sampling depth of photoelectrons excited with $\mathrm{Al} \mathrm{K} \alpha$ is roughly about $3 \mathrm{~nm}$ or so, the measured composition given by XPS corresponds to the composition in the surface region. The XPS studies showed the increase of the total fraction of $\mathrm{Pd}$ and $\mathrm{Pt}(57 \%)$ and the decrease of the fraction of $\mathrm{Cu}(43 \%)$ in the surface region (Fig. 1b) compared to those before thermal annealing owing to adsorption-induced segregation of $\mathrm{Pt}$ and $\mathrm{Pd}$ in $\mathrm{H}_{2}$ at $500{ }^{\circ} \mathrm{C}$. In addition, the XRD pattern of $\mathrm{PtPdCu}$ showed the formation of a $\mathrm{Cu}$ core upon thermal annealing (ESI, $\uparrow$ Fig. S4).

After the thermal treatment, electrochemical potential cycling was performed (Fig. 1c). A decrease of the $\mathrm{Cu}$ peak in CVs from the 0th to the 250th cycle identified in Fig. S5a (ESI $\dagger$ ) showed the leaching of $\mathrm{Cu}$ in the topmost surface layers. Notably, the electrochemical active surface area (ECSA) after the leaching of surface $\mathrm{Cu}$ was even further 

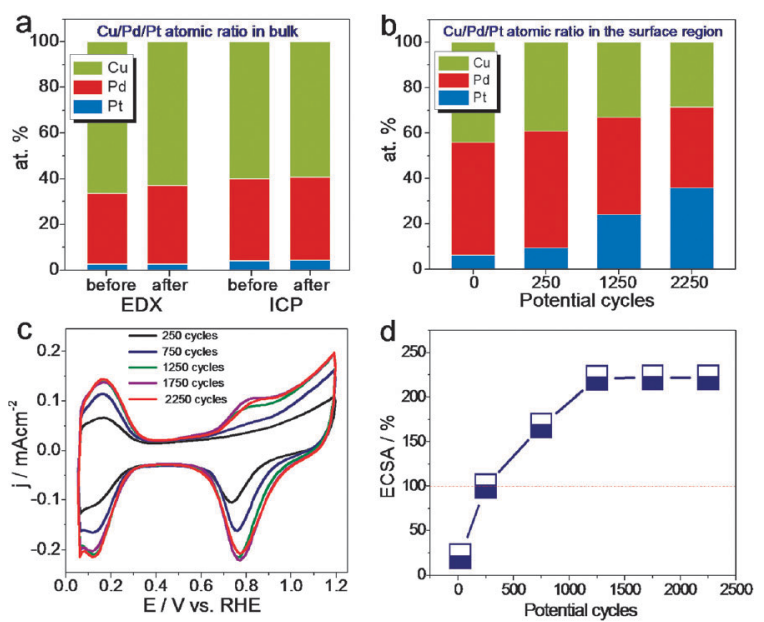

Fig. 1 (a) The composition of PtPdCu measured by EDX and ICPMS before and after potential cycling. The atomic ratio of $\mathrm{Pt} / \mathrm{Pd} / \mathrm{Cu}$ prior to potential cycling is about 4/36/60. (b) Atomic ratio of Pt, $\mathrm{Pd}$ and $\mathrm{Cu}$ in the surface region (from the topmost surface layer down to $\sim 3 \mathrm{~nm}$ deep) characterized with XPS; the $\mathrm{Pt} / \mathrm{Pd}$ atomic ratio and the atomic fraction of $\mathrm{Pt}$ increase with increasing number of potential cycles. (c) CVs of the PtPdCu tubes recorded at $50 \mathrm{mV} \mathrm{s}^{-1}$ in Arsaturated $0.1 \mathrm{M} \mathrm{HClO}_{4}$ after different potential cycles. (d) Relative ECSA calculated with CVs in (c) upon potential cycling (the relative ECSA was calculated by dividing the ECSA after a certain number of potential cycles by that at the 250th cycle). The first relative ECSA was obtained after the 20th potential cycle. It clearly shows the increase of ECSA with the increase of potential cycling. After 1250 cycles, the ECSA keeps the same.

increased after the 250th potential cycle (Fig. 1c and d; Fig. S5 in ESI $\dagger)$. Fig. $1 \mathrm{~b}$ shows that the atomic fraction of $\mathrm{Cu}$ measured with XPS is decreased from $44 \%$ at the 0 th cycle and $40 \%$ at the 250 th cycle, suggesting leaching of a very few subsurface $\mathrm{Cu}$ atoms in this process (ESI, $\dagger$ Fig. S6). ${ }^{12}$ The TEM image in Fig. S2b (ESI $\dagger$ ) upon 250th potential cycling shows an obvious gully-like contrast different from that in Fig. S2a (ESI $\dagger$ ), suggesting the formation of a rough surface upon potential cycling. Compared with the ECSA after 20 cycles (about $12 \mathrm{~cm}^{2} \mathrm{mg}_{\mathrm{Pt}+\mathrm{Pd}}{ }^{-1}$ ), 4 times and 10 times ECSA gains were obtained after 250 th and 1250 th cycles, respectively (Fig. 1d). The ECSA reached the maximum at around the 1250 th potential cycle (about $3 \mathrm{~h} ; 250 \mathrm{mV} \mathrm{s}^{-1}$ ) and then kept at the same value after the 1250 th cycle. The roughness results from the leaching of surface $\mathrm{Cu}$ and the concomitant geometric restructuring during the potential cycling. ${ }^{6 a}$

XPS studies of the PtPdCu catalyst after a certain number of potential cycles (Fig. 1b) uncovered an obvious increase of the fraction of $\mathrm{Pt}$ atoms in the surface region at the 1250th cycle compared with the 250th cycle and showed a continuous increase upon potential cycling from the 1250th to 2250th cycle. In fact, the atomic fraction of $\mathrm{Pt}$ in the total fraction of $\mathrm{Pt}$ and $\mathrm{Pd}$ in the surface region characterized with XPS increased from $9.5 \%$ Pt at the 250th cycle to $35 \%$ at the 2250 th cycle (Fig. 1b). These results clearly show the enrichment of atomic fractions of $\mathrm{Pt}$ and $\mathrm{Pd}$ in the surface during potential cycling (from the 0th to the 2250th cycle) though the overall composition of $\mathrm{Pt}, \mathrm{Pd}$, and $\mathrm{Cu}$ in the whole ternary catalyst from the 250th to the 2250th cycle does not show an obvious change on the basis of energy dispersive X-ray spectroscopy (EDX) and inductively coupled plasma mass spectrometry (ICP-MS).

The variation of the alloy compositions in the surface region changed the peak intensity of the shake-up satellite of $\operatorname{Pd}_{3 \mathrm{~d}}$ (ESI, $\uparrow$ Fig. S7), suggesting the modification of the chemical environments and electronic structure of $\mathrm{Pd}$ atoms. The enrichment of $\mathrm{Pt}$ under electrochemical conditions is decided by the surface segregation energy of ternary $\mathrm{PtPdCu}$ and adsorption energy of species. ${ }^{10 b}$

Therefore, the enrichment of the surface Pt in the topmost surface layer can be used to study the site-dependent formic acid oxidation in situ upon potential cycling. ${ }^{13}$ For the formic acid oxidation, it is well recognized that the electro-oxidation of $\mathrm{HCOOH}$ to $\mathrm{CO}_{2}$ proceeds through two parallel pathways: direct oxidation to $\mathrm{CO}_{2}$ (pathway I) and oxidation to $\mathrm{CO}_{2}$ through the adsorption of the CO intermediate (pathway II). ${ }^{13 a, 14}$ In the direct oxidation (pathway I), the $\mathrm{HCOOH}$ molecules dehydrogenate to form $\mathrm{CO}_{2}$ directly through one or more active intermediates. Alternatively, pathway II involves $\mathrm{HCOOH}$ dehydrogenation to form $\mathrm{CO}$ and subsequent electro-oxidation of the adsorbed $\mathrm{CO}$ to $\mathrm{CO}_{2}$ at high potentials. For pathways I and II, the peak intensity appears at 0.35 and $0.9 \mathrm{~V}$, respectively. However, it is still quite challenging to achieve both pathways only in one catalyst.

Active sites consisting of neighboring two or three Pt atoms (dimer or trimer of Pt atoms) are required for pathway II. ${ }^{13 b, 14}$ In the case of the surface with low content $\mathrm{Pt}$, the sites of a single $\mathrm{Pt}$ atom surrounded by $\mathrm{Pd}$ atoms favor the direct oxidation of formic acid on these surfaces through the dehydrogenation of formic acid (pathway I). If more Pt atoms segregate to the topmost surface layer upon more potential cycles, the density of dimers and trimers of $\mathrm{Pt}$ atoms on the topmost surface is increased. The increase of the atomic fraction of Pt and density of sites of dimers and trimers on the surface will enhance the adsorption of $\mathrm{CO}_{\mathrm{ad}}$ on the surface, which favors pathway II and gives a high current density $i_{\mathrm{c} \cdot}{ }^{13 b-d}$ Here, electrochemical measurements of formic acid oxidation were performed on catalysts, which experienced different potential cycles (250th, 750th, 1250th, 1750th, and 2250th) as shown in Fig. 2.

The observed increase of the peak current density $i_{\mathrm{c}}$ at $+0.9 \mathrm{~V}$ (pathway II) and the corresponding decrease of the current density $i_{f}$ at $+0.35 \mathrm{~V}$ (pathway I) with the increase of the number of the potential cycles suggest the increase of $\mathrm{Pt}$ atoms on the topmost surface layer of the catalyst though this study couldn't provide the exact concentration of $\mathrm{Pt}$ in the topmost surface layer. Scheme 1 illustrates the migration of $\mathrm{Pt}$ atoms to the topmost surface layer and the switch of the reaction pathway of formic acid oxidation with the increase of potential cycles (atomic redistribution on the topmost surface layer). Notably, the absence of the $\mathrm{Cu}$ peak at $+0.6 \mathrm{~V}$ shows that there is no $\mathrm{Cu}$ in the topmost surface layer. Thus, we can conclude that the potential cycling forms a mixed PtPd surface and a $\mathrm{Cu}$-rich core. In addition, it suggested the enrichment of Pt concentration from the 0 th to the 2250th cycle. We believe that if the potential cycling is performed more than 2250 cycles the $\mathrm{Pt} / \mathrm{Pd}$ atomic ratio will still show a detectable change in the surface region. However, the most sensitive active site for formic acid oxidation is that with less $\mathrm{Pt}$ on the surface 


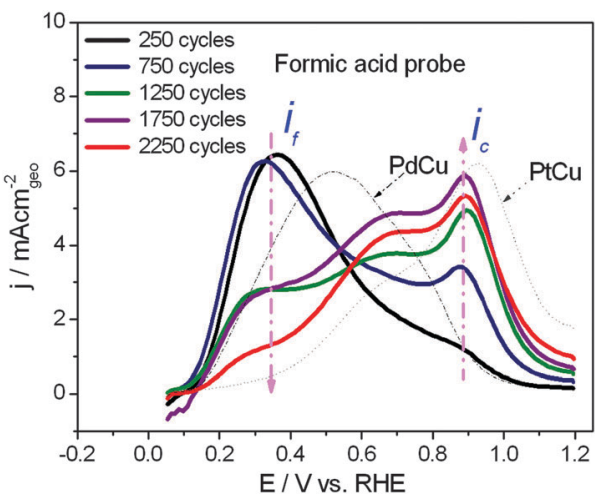

Fig. $2 \mathrm{CVs}$ of the formic acid oxidation through the positive scan after a different number of potential cycles. After a certain number of potential cycles in Ar-saturated $0.1 \mathrm{M} \mathrm{HClO}_{4}$ solution, the electrode was transferred into Ar-saturated $0.1 \mathrm{M} \mathrm{HClO}_{4}+0.1 \mathrm{M} \mathrm{HCOOH}$ solution, and the polarization curves were recorded. $i_{\mathrm{f}}$ represents the peak current intensities of direct oxidation of $\mathrm{HCOOH}$ to $\mathrm{CO}_{2}$ in pathway $\mathrm{I}$ and $i_{\mathrm{c}}$ denotes the peak current intensities of oxidation to $\mathrm{CO}_{2}$ through the formation of an intermediate $\mathrm{CO}$ in pathway II.

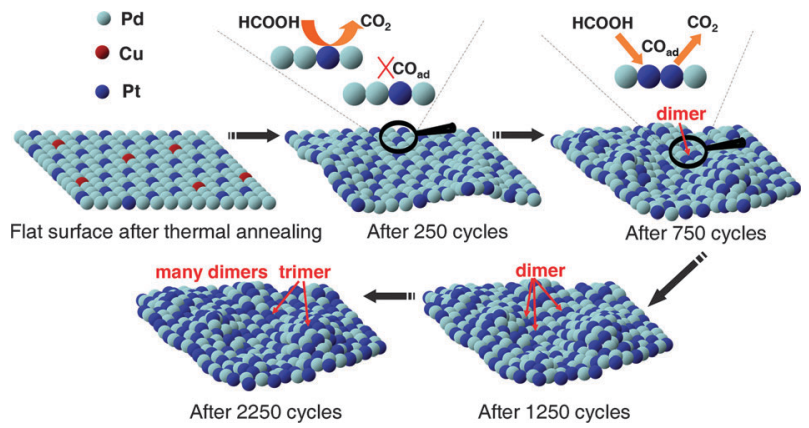

Scheme 1 Schematic illustration of the active site-dependent formic acid oxidation, the morphology restructuring and surface atomic redistribution of the surfaces after a different number of potential cycles. The surface roughness resulted in the enhancement of the ECSA. The relative atomic ratio of $\mathrm{Pt}$ to $\mathrm{Pd}$ increased continuously upon potential cycling owing to the atomic redistribution, which contributed to the different formic acid oxidation pathway.

(Pt monomer surrounded by $\mathrm{Pd}$ atoms) that is why we design the starting materials with much less Pt content.

In summary, we have investigated the active site-dependent electrochemical formic acid oxidation reaction by surface atomic redistribution upon potential cycling in an acidic electrolyte. The increased Pt coverage on a mixed PtPd alloy surface of ternary PtPdCu changes the electrochemical formic oxidation mechanism and contributes to the peak current density ratio alteration. This work also suggests a new avenue for understanding the degradation and the enhancement of catalytic activity by surface atomic redistribution in the topmost layer.

This work is supported by the National Basic Research Program of China (Grant 2010CB934700), the National Natural Science Foundation of China (Grants 91022032, 21061160492, J1030412), the Chinese Academy of Sciences
(Grant KJZD-EW-M01-1), the International Science \& Technology Cooperation Program of China (Grant 2010DFA41170), the Principal Investigator Award by the National Synchrotron Radiation Laboratory at the University of Science and Technology of China, and the University of Notre Dame.

\section{Notes and references}

1 (a) H. A. Gasteiger and N. M. Markovic, Science, 2009, 324, 48-49; (b) P. Strasser, S. Koh, T. Anniyev, J. Greeley, K. More, C. F. Yu, Z. C. Liu, S. Kaya, D. Nordlund, H. Ogasawara, M. F. Toney and A. Nilsson, Nat. Chem., 2010, 2, 454-460.

2 (a) R. R. Adzic, J. Zhang, K. Sasaki, M. B. Vukmirovic, M. Shao, J. X. Wang, A. U. Nilekar, M. Mavrikakis, J. A. Valerio and F. Uribe, Top. Catal., 2007, 46, 249-262; (b) M. Shao, K. Shoemaker, A. Peles, K. Kaneko and L. Protsailo, J. Am. Chem. Soc., 2010, 132, 9253; (c) W. P. Zhou, X. F. Yang, M. B. Vukmirovic, B. E. Koel, J. Jiao, G. W. Peng, M. Mavrikakis and R. R. Adzic, J. Am. Chem. Soc., 2009, 131, 12755-12762.

3 (a) V. R. Stamenkovic, B. S. Mun, K. J. J. Mayrhofer, P. N. Ross and N. M. Markovic, J. Am. Chem. Soc., 2006, 128, 8813-8819; (b) V. R. Stamenkovic, B. S. Mun, M. Arenz, K. J. J. Mayrhofer, C. A. Lucas, G. F. Wang, P. N. Ross and N. M. Markovic, Nat. Mater., 2007, 6, 241-247.

4 (a) R. Srivastava, P. Mani, N. Hahn and P. Strasser, Angew. Chem., Int. Ed., 2007, 46, 8988-8991; (b) S. Koh and P. Strasser, J. Am. Chem. Soc., 2007, 129, 12624-12625.

5 (a) C. Koenigsmann, A. C. Santulli, K. Gong, M. B. Vukmirovic, W.-P. Zhou, E. Sutter, S. S. Wong and R. R. Adzic, J. Am. Chem. Soc., 2011, 133, 9783-9795; (b) C. Koenigsmann, W. P. Zhou, R. R. Adzic, E. Sutter and S. S. Wong, Nano Lett., 2010, 10, 2806-2811.

6 (a) C. H. Cui, H. H. Li, X. J. Liu, M. R. Gao and S. H. Yu, Acs Catal., 2012, 2, 916-924; (b) C. H. Cui, H. H. Li and S. H. Yu, Chem. Sci., 2011, 2, 1611-1614.

7 (a) F. Tao and M. Salmeron, Science, 2011, 331, 171-174; (b) F. Tao, S. Dag, L. W. Wang, Z. Liu, D. R. Butcher, M. Salmeron and G. A. Somorjai, Nano Lett., 2009, 9, 2167-2171; (c) F. Tao, S. Dag, L. W. Wang, Z. Liu, D. R. Butcher, H. Bluhm, M. Salmeron and G. A. Somorjai, Science, 2010, 327, 850-853.

8 F. Tao, M. E. Grass, Y. W. Zhang, D. R. Butcher, J. R. Renzas, Z. Liu, J. Y. Chung, B. S. Mun, M. Salmeron and G. A. Somorjai, Science, 2008, 322, 932-934.

9 K. J. J. Mayrhofer, V. Juhart, K. Hartl, M. Hanzlik and M. Arenz, Angew. Chem., Int. Ed., 2009, 48, 3529-3531.

10 (a) J. Zhang, M. B. Vukmirovic, K. Sasaki, A. U. Nilekar, M. Mavrikakis and R. R. Adzic, J. Am. Chem. Soc., 2005, 127, 12480-12481; (b) G. E. Ramirez-Caballero, Y. Ma, R. Callejas-Tovar and P. B. Balbuena, Phys. Chem. Chem. Phys., 2010, 12, 2209-2218.

11 H. H. Li, C. H. Cui, S. Zhao, H. B. Yao, M. R. Gao, F. J. Fan and S. H. Yu, Adv. Energy Mater., 2012, 2, 1182-1187.

12 C. H. Cui, X. J. Liu, H. H. Li, M. R. Gao, H. W. Liang, H. B. Yao and S. H. Yu, Chemcatchem, 2012, 4, 1560-1563.

13 (a) F. J. Vidal-Iglesias, J. Solla-Gullón, E. Herrero, A. Aldaz and J. M. Feliu, Angew. Chem., Int. Ed., 2010, 49, 6998-7001; (b) H. X. Zhang, C. Wang, J. Y. Wang, J. J. Zhai and W. B. Cai, J. Phys. Chem. C, 2010, 114, 6446-6451; (c) N. Kristian, Y. Yan and X. Wang, Chem. Commun., 2008, 353-355; (d) Q. Yuan, Z. Zhou, J. Zhuang and X. Wang, Chem. Commun., 2010, 46, 1491-1493.

14 (a) O. Winjobi, Z. Y. Zhang, C. H. Liang and W. Z. Li, Electrochim. Acta, 2010, 55, 4217-4221; (b) M. Arenz, V. Stamenkovic, T. J. Schmidt, K. Wandelt, P. N. Ross and N. M. Markovic, Phys. Chem. Chem. Phys., 2003, 5, 4242-4251. 